\title{
Down-to-earth medical benefits of space research
}

What do cordless power tools, scratchresistant lenses and athletic shoes have in common? Space research. They are all spinoffs from technology developed as part of the space programme.

At a meeting held last month in Houston, Texas, home of the Lyndon B. Johnson Space Center, space scientists, government officials and representatives from the biomedical and investment communities met together under one roof to look at the lessons of the past and to discuss how best to bring the benefits of space medicine research down to earth.

The meeting was held partly in response to a call by the White House for greater cooperation between NASA and other government agencies and was organized jointly by the National Aeronautics and Space Administration (NASA) and the American Institute of Aeronautics and Astronautics, which represents more than 35,000 aerospace professionals.

In his opening address, NASA Administrator Daniel Goldin outlined his vision for change at the agency. "The NASA of the $60 \mathrm{~s}$ must be left behind if we are to meet the challenges of the 21st century." In the days of Apollo, NASA garnered 4.5 per cent of the national budget; now the figure is 0.8 per cent, and dropping, said Goldin.

In the life sciences, that vision includes forming stronger ties with the US National Institutes of Health and the biomedical community at large, the National Science Foundation and the Department of Defense (DoD). In short, the agency is on notice that it must be more proactive in translating the benefits of space research into tangible medical and other benefits. To do this, Goldin said NASA must cut its design cycles (now between 3 and 5 years), as this causes investors to shy away.

Goldin and others spoke of the challenges and opportunities that will be provided by the proposed international space station, which is currently scheduled to be completed by 2002 . What, for example, will be the long-term effects of radiation exposure on crews on the space station (due to the higher inclination of $51.6^{\circ}$, higher planned altitude of 222 miles, and increased risk of radiation exposure from solar flare particles)?

Long-duration space flight could reveal much about the human condition, particularly relating to cardiovascular and regulatory physiology, the sensori-motor and musculoskeletal system. Moreover, multi- generational mammalian developmental studies will now be possible, and opportunities will be provided in the areas of drug development (for example, in drug encapsulation and structure-based drug design), cell culture and tissue modelling (in the three-dimensional growth of cell aggregates), and in telemedicine (treating people in remote locations), in which DoD has shown considerable interest.

In his keynote speech, Michael De Bakey, heart transplant surgeon and chancellor of Baylor College of Medicine, Houston, Texas, spoke of his long-standing relationship with NASA, which began informally when a heart transplant patient of his (who happened to be a NASA employee) became interested in research being undertaken at Baylor to develop an external auxiliary left ventricle, or 'left ventricular-assist device'. The patient feit that NASA engineers in Houston, with their expertise in the miniaturization of pumps for the space programme, could be of some help.

The development of such a device (or, an artificial heart) could have a significant impact, not only in terms of relieving patient suffering, but also in drastically reducing health-care costs, which, De Bakey estimates, may run to between $\$ 10$ and 20 billion a year in the United States. Moreover, an estimated 50,000 to 150,000 people in the United States alone could benefit.

Tests carried out in calves have shown that the device can generate $100 \mathrm{~mm} \mathrm{Hg}$ pressure (the mean normal pressure is $70-80 \mathrm{~mm} \mathrm{Hg}$ ), can pump between five and six litres of blood per minute (which is comparable with normal rates), and does not cause unacceptable levels of red blood cell destruction. De Bakey hopes to begin clinical trials with this external device early next year, but the longer term aim is to develop an implantable version of the pump, driven by a battery that can be recharged through the skin.

Space research is also being applied to health problems in developing countries. Philip Njemanze from the Chidicon Medical Center in Owerri, Nigeria, is working with NASA in the area of disease surveillance and risk assessment for malaria. Using a combination of satellite imagery, provided by NASA, and field data from the local region, Njemanze hopes to be able to monitor the location and extent of the habitat of the anopheline mosquito, the vector responsible for transmitting the disease. Such data will then be used to de- velop predictive models of transmission risk and, hence, a strategy for malaria prevention. Similar methods are being used with other vector-borne diseases: trypanosomiasis, onchocerciasis and Lyme disease (in the United States).

One area where space research could have a significant impact on life science research, according to Larry DeLucas of the University of Alabama at Birmingham, and chief scientist for the space station, is in the 'growth' of biologically important macromolecules for analysis by X-ray crystallography (particularly those of 15,000 daltons or more which cannot be analysed with atomic resolution by other methods).

The critical first step in obtaining the 3-D structure of a molecule is protein crystal growth, which - by all accounts - is more of a 'black art' than a science. Once the structure is known, drugs can be tailormade to block the active site of a molecule.

Obtaining crystals that are large enough and of a high enough quality is the current bottleneck in structure-based drug design said DeLucas. The situation in space, however, is different. Delucas, who has had first-hand experience as payload specialist on the USML-1 shuttle mission, said that many of the crystals grown in space "do diffract significantly beyond their Earthbound counterparts."

The crystallography facilities on space station will help relieve that bottleneck, said DeLucas. The hope is not only to grow crystals in space but also to perform X-ray data collection 'on orbit', relaying it back to Earth using data downlink facilities.

While DeLucas and others, including Senator Kay Bailey Hutchison (Republican, Texas), are clearly excited by the prospect of the space station and the long-duration space flight opportunities that it will provide, they are also aware of what can happen to 'Big Science' projects during a budget squeeze. Most notable was the demise in 1993 of the Superconducting Supercollider.

But, in a way, Bailey Hutchison, a native Texan and self-confessed "space junkie", was preaching to the converted when she vowed not to allow Congress "to give up the seed corn that will give our kids the jobs of the future." Hutchison must continue to make her message heard above the din (of budget cutters) back in Washington, DC and, NASA - at a turning point in its development - must deliver on its promise.

DLANE GERSHON Houston 